DOI 10.37882/2223-2974.2021.03.03

\title{
ФОРМИРОВАНИЕ ЭФФЕКТИВНОГО ИНВЕСТИЦИОННОГО ПОРТФЕЛЯ ЦЕННЫХ БУМАГ НА ОСНОВЕ АНАЛИЗА АКЦИЙ И РЫНКА
}

\section{FORMATION OF AN EFFECTIVE INVESTMENT PORTFOLIO OF SECURITIES BASED ON STOCK AND MARKET ANALYSIS}

F. Akmedov

A. Kochaa

Summary: In this article, the author analyzes the shares of the largest companies, as well as the analysis of the market as a whole, on the basis of which the most effective option for forming an investment portfolio of securities is determined. In addition, the article collects and systematizes theoretical approaches to the essence of the securities market, summarizes the existing methodological basis for its formation.

Keywords: securities market, market formation, securities portfolio, investment portfolio, shares.

Портфель ценных бумаг - это определенным образом подобранная совокупность отдельных видов ценных бумаг. В зависимости от того, какие цели и задачи изначально стоят при формировании того или иного портфеля, выбирается определенное процентное соотношение между различными типами активов, составляющими портфель инвестора [1, с.45].

Каждый инвестор, составляя свой портфель с ценными бумагами, хочет получить доход, чтобы этого достичь необходимо наполнить портфель такими бумагами, которые бы принесли максимальный доход при минимальном риске. Но может ли инвестор на сто процентов определить, какая бумага соответствует данным критериям? Нет, инвестор может лишь только предполагать сколько та или иная бумага принесет ему доход, основываясь на прошлых данных, а также на собственном опыте. Однако чаще всего опытные инвесторам удается собрать портфель, который принесет им необходимый доход за период, который он сам установил. Для этого он использует индикаторы, которые оценивают предполагаемую доходность бумаги, а также риск, заложенный в ней.

Первый рассмотренным индикатором будет ожидаемая доходность портфеля, так как если спросить инвестора, что он хочет достичь, покупая ту или иную ценную бумага, то, скорее всего, он вам ответит, что хочет полу-
Ахмедов Фахраддин Насраддин оглы К.э.н., дочент, Российский университет дружбы народов Akmedov-fn@rudn.ru

Кочаа Айгуль Оюн-ооловна

Российский университет дружбы народов kochaa.a@mail.ru

Аннотация: В данной статье автором проводится анализ акций крупнейших компаний, а также анализ рынка в целом, на основе которого определяется наиболее эффективный вариант формирования инвестиционного портфеля ценных бумаг. Кроме того, в статье собраны и систематизированы теоретические подходы к сущности рынка ценных бумаг, обобщена имеющаяся методологическая база для его формирования.

Ключевые слова: рынок ценных бумаг, формирование рынка, портфель ценных бумаг, инвестиционный портфель, акции.

чить с неё доход. Именно для этого рассчитывается ожидаемая норма доходности.

Ожидаемая доходность рассчитывается по формуле $[2$, c.53]:

$$
K=\sum_{i=1}^{n} P i * K i
$$

Где К - ожидаемая доходность портфеля;

$\mathrm{Pi}$ - ожидаемая доходность i-ой ценной бумаги, за период времени; Кi - доля і-ой ценной бумаги в портфеле.

С нахождение коэффициента данного выше инвестор может предполагать доходность как отдельной ценной бумаги, так и портфеля в целом.

Для расчета рисков чаще всего используют:

1. Стандартное отклонение доходности портфеля и каждого актива в отдельности от доходности рынка (стандартное отклонение);

2. Коэффициент Шарпа;

3. Коэффициент бета;

4. Коэффициент Трейнора;

5. Коэффициента Альфа Дженсена.

Стандартное отклонение доходности портфеля, рас- 
считывается по формуле:

$$
\sigma_{P}=\sqrt{\sum_{i=1}^{N} w_{i}^{2} \cdot \sigma^{2}\left(k_{i}\right)+\sum_{i=1}^{N} \sum_{i \neq j}^{N} w_{i} \cdot w_{j} \cdot \operatorname{Cov}\left(k_{i}, k_{j}\right)}
$$

Где N - количество активов (ценных бумаг), входящих в портфель; wi - удельный вес і-го актива в портфеле;

wj - удельный вес j-го актива в портфеле;

$\sigma(\mathrm{ki})$ - стандартное (среднеквадратическое) отклонение доходности і-го актива;

$\operatorname{Cov}(\mathrm{ki}, \mathrm{kj})$ - ковариация доходности i-го и j-го актива.

Представленную выше формулу можно преобразовать, используя формулу коэффициента корреляции.

$$
R_{k_{i}, p}=\frac{\operatorname{Cov}\left(k_{i}, p\right)}{\sigma_{k_{i}} \cdot \sigma_{p}}
$$

Где $\sigma(\mathrm{kj})$ - стандартное (среднеквадратическое) отклонение доходности і-го актива.

Для расчета коэффициента корреляции используется ковариация, которая высчитывается по формуле:

$$
\operatorname{Cov}\left(k_{i}, k_{p}\right)=\frac{\sum_{i=1}^{n}\left(k_{i}-\hat{k}\right) \cdot\left(p_{i}-\hat{p}\right)}{n-1}
$$

Где ki - доходность ценной бумаги в і-ом периоде;

- ожидаемая (средняя) доходность ценной бумаги;

рі - доходность портфеля в і-ом периоде;

- ожидаемая (средняя) доходность портфеля;

$\mathrm{n}$ - количество наблюдений.

Коэффициент Шарпа необходим, чтобы определять, какую доходность инвестор получит от портфеля за единицу риска, то есть коэффициент Шарпа должен быть выше единицы, чтобы риск потери вложенных денежных средств [3].

Рассчитывается по формуле:

$$
S(X)=\frac{\operatorname{avg} R(X)-\operatorname{avg} R_{f}}{\sigma(X)}
$$

Где:

$\operatorname{avg} \mathrm{R}(\mathrm{X})$ - среднеарифметическое значение доходности портфеля, для которого рассчитывается коэффициент;

avg Rf - среднеарифметическое значение доходности безрискового актива.

$\sigma(X)$ - стандартное отклонение доходности портфеля $\mathrm{X}$.

Также, как и коэффициент Шарпа с помощью коэффициента бета рассчитывается риск, однако делается это путем отражения риска портфеля по сравнению с рынком, в роли которого выступает среднерыночный портфель. С помощью данного коэффициента можно оценить, насколько акция чувствительна к изменениям на рынке[4].

Формула расчета:

$$
\beta=\frac{\operatorname{Cov}\left(r_{i}, r_{m}\right)}{\sigma_{m}^{2}} ;
$$

Где: $\beta$ - коэффициент бета, мера систематического риска (рыночного риска);

ri - доходность і-й акации (инвестиционного портфеля); rm - рыночная доходность;

б2m - дисперсия рыночной доходности.

Если коэффициент бета:

1. Равен единице, то степень риска портфеля сопоставим с рынком

2. Меньше единицы, риск ниже, чем в среднем по рынку

3. Больше единицы, риск выше, чем с среднем по рынку.

Из выше сказанного можно сделать вывод, что коэффициент бета должен быть ниже единицы, что уменьшить риск портфеля.

Коэффициент Трейнора необходим, чтобы сравнить доходность и безрисковою ставку. Другими словами, необходимо понять, имеет ли смысл вкладывать денежные средства в портфель, сравнив его доходность с доходностью, которую инвестор может получить от банка за вклад под определенный процент, который зависит от страны, где торгует инвестор. Ведь, если доходность от вклада средств на депозит в банк будет сопоставима с доходностью портфеля, то не имеет смысл рисковать и формировать портфель с ценными бумагами [5].

$$
R V O L_{p}=\frac{a r_{p}-a r_{f}}{\beta_{p}} ;
$$

Где, Arp - Ожидаемая доходность портфеля; Arf Ожидаемая доходность рынка;

Вр - коэффициент бета.

Коэффициента Альфа Дженсена был предложен в 1968 году. Его еще называют коэффициентом альфа. Используется для оценки эффективности портфеля, путем сравнения его доходности с рыночной доходностью. Иными словами, коэффициент альфа показывает потенциал доходности ценной бумаги или портфеля по сравнению с рыночной доходностью [6].

$$
\alpha_{p}=\alpha r_{p}-\left[a r_{f}+\left(a r_{m}-a r_{f}\right) \beta_{p}\right]
$$

Где arp - средняя доходность портфеля; 
Arf - доходность безрискового актива; Arm - средняя доходность рынка;

Вр - бета коэффициент.

Используя данные формулы можно провести анализ эффективности портфеля. Для примера портфель будет состоять из акций 5 разных компаний из России. Предполагаемая инвестируемая сумма 150000 рублей. Срок существования портфеля два года. Дата покупки акций 20 марта 2019 года. Срок для оценки 9 месяцев.

Компании, чьи акции будут исследованы портфеле ценных бумаг:

1. Публичное акционерное общество «Сбер- банк России», акция обыкновенная (количество бумаг в лоте - 10). Актив - А.

2. Публичное акционерное общество «Нефтяная компания «Лукойл», акция обыкновенная (количество бумаг в лоте - 1). Актив - Б.

3. Публичное акционерное общество «КАМАЗ», акция обыкновенная (количество бумаг в лоте 100). Актив - В.

4. Публичное акционерное общество «РБК», акция обыкновенная (количество бумаг в лоте - 100). Актив - Г,

5. Публичное акционерное общество «Северсталь», акция обыкновенная (количество бумаг в лоте 10). Актив - Д.

Таблица 1.

Котировки Сбербанка за 9 месяцев.

\begin{tabular}{|l|c|c|c|c|c|c|c|c|c|}
\hline Сбербанк & 20.04 & 20.05 & 20.06 & 20.07 & 20.08 & 20.09 & 20.10 & 20.11 & 20.12 \\
\hline Цена Фактическая, Руб. & 204,34 & 191,2 & 191,16 & 180,7 & 194,21 & 189,3 & 207,17 & 206,89 & 209,8 \\
\hline Кол-во, шт. & 190 & 190 & 190 & 190 & 190 & 190 & 190 & 190 & 190 \\
\hline Общая Стоимость, руб. & 38824,6 & 36328 & 36320,4 & 34333 & 36899,9 & 35967 & 39362,3 & 36309,1 & 39862 \\
\hline Доходность, в процентах & & $-6,43$ & $-0,02$ & $-5,47$ & 7,47 & $-2,52$ & 9,44 & $-0,13$ & 1,40 \\
\hline
\end{tabular}

Котировки Лукойл за 9 месяцев.

\begin{tabular}{|l|c|c|c|c|c|c|c|c|c|}
\hline Лукойл & 20.04 & 20.05 & 20.06 & 20.07 & 20.08 & 20.09 & 20.10 & 20.11 & 20.12 \\
\hline Цена Фактическая, Руб. & 4300 & 4386 & 4701 & 4673,5 & 4809,5 & 4808,5 & 5200 & 5445 & 5770 \\
\hline Кол-во, шт. & 8 & 8 & 8 & 8 & 8 & 8 & 8 & 8 & 8 \\
\hline Общая Стоимость, руб. & 34400 & 35088 & 37608 & 37388 & 38476 & 38468 & 41600 & 43560 & 46160 \\
\hline Доходность, в процентах & & 2 & 7,18 & $-0,58$ & 2,91 & $-0,02$ & 8,14 & 4,71 & 5,96 \\
\hline
\end{tabular}

Котировки КАМАЗ за 9 месяцев

\begin{tabular}{|l|c|c|c|c|c|c|c|c|c|}
\hline КАМАЗ & 20.04 & 20.05 & 20.06 & 20.07 & 20.08 & 20.09 & 20.10 & 20.11 & 20.12 \\
\hline Цена Фактическая, Руб. & 61,35 & 62,1 & 66 & 59,4 & 55,3 & 53 & 60,7 & 59,1 & 55 \\
\hline Кол-во, шт. & 300 & 300 & 300 & 300 & 300 & 300 & 300 & 300 & 300 \\
\hline Общая Стоимость, руб. & 18405 & 18630 & 19800 & 17820 & 16590 & 15900 & 18210 & 17730 & 16500 \\
\hline Доходность, в процентах & & 1,22 & 6,28 & -10 & $-6,9$ & $-4,15$ & 14,52 & $-2,63$ & $-6,93$ \\
\hline
\end{tabular}

Котировки РБК за 9 месяцев

\begin{tabular}{|l|c|c|c|c|c|c|c|c|c|}
\hline РБК & 20.04 & 20.05 & 20.06 & 20.07 & 20.08 & 20.09 & 20.10 & 20.11 & 20.12 \\
\hline Цена Фактическая, Руб. & 5,04 & 4,8 & 4,435 & 4,14 & 3,968 & 3,956 & 4,02 & 3,936 & 3,854 \\
\hline Кол-во, шт. & 3100 & 3100 & 3100 & 3100 & 3100 & 3100 & 3100 & 3100 & 3100 \\
\hline Общая Стоимость, руб. & 15624 & 14880 & 13748,5 & 12834 & 12300,8 & 12263,6 & 12462 & 12201,6 & 11947,4 \\
\hline Доходность, в процентах & & $-4,76$ & $-7,6$ & $-6,65$ & $-4,15$ & $-0,3$ & 1,61 & $-2,08$ & $-2,08$ \\
\hline
\end{tabular}

Таблица 5.

Котировки Северсталь за 9 месяцев

\begin{tabular}{|l|c|c|c|c|c|c|c|c|c|}
\hline Северсталь & 20.04 & 20.05 & 20.06 & 20.07 & 20.08 & 20.09 & 20.10 & 20.11 & 20.12 \\
\hline Цена Фактическая, Руб. & 972,5 & 1045 & 1098,5 & 1054,5 & 1005 & 962,5 & 950 & 1007,8 & 1013,4 \\
\hline Кол-во, шт. & 35 & 35 & 35 & 35 & 35 & 35 & 35 & 35 & 35 \\
\hline Общая Стоимость, руб. & 34037,5 & 36575 & 38447,5 & 36907,5 & 35175 & 33687,5 & 33250 & 35273 & 35469 \\
\hline Доходность, в процентах & & 7,45 & 5,11 & -4 & 4,69 & $-4,22$ & $-1,29$ & 6,08 & 0,55 \\
\hline
\end{tabular}


Из данных (Таблица 6), можно увидеть, что за восемь месяцев доходность портфеля составляет 10,53\% или 1,31\% в месяц или 31,59\% за два года.

Рассчитаем доходность рынка за выбранный период, суммируя данные доходности за восемь месяцев (Таблица 7). Доходность, в процентах составляет 11,17\%.

С доходностью индекса ММВБ будем сравнивать доходность портфеля с ценными бумагами.

Собранный портфель представляет собой совокупность акций Российских компаний, причем они находятся в разных отраслях, что уже делает портфель диверси-

\section{фицированным.}

После того, как были собраны данные первое, что должен рассчитать инвестор - это стандартное отклонение портфеля, которое показывает риск изменения ожидаемой доходности портфеля. Чем выше стандартное отклонение, тем, соответственно, выше риск.

Для расчета стандартного отклонения портфеля необходимо рассчитать корреляцию каждого актива с каждым, а также стандартное отклонение каждого актива, а затем воспользоваться формулой (1).

Используя данный (таблица 8, 9), а также формулу (4),

Доходность портфеля за восемь месяцев

\begin{tabular}{|l|c|c|c|c|c|c|}
\hline & Сбербанк & Лукойл & РБК & КАМАЗ & Северсталь & 0бщее \\
\hline Общая доходность за 8 месяцев, в процентах & 3,73 & 30,3 & $-8,6$ & $-0,26$ & 4,98 & \\
\hline Доля в портфеле & 0,26 & 0,3 & 0,11 & 0,07 & 0,23 & \\
\hline Доходность для портфеля, в процентах & 0,96 & 9,09 & $-0,94$ & $-0,01$ & 1,14 & 10,53 \\
\hline
\end{tabular}

Котировки ММВБ за 9 месяцев

\begin{tabular}{|l|c|c|c|c|c|c|c|c|c|}
\hline ММВБ & 20.04 & 20.05 & 20.06 & 20.07 & 20.08 & 20.09 & 20.10 & 20.11 & 20.12 \\
\hline Цена Фактическая, Руб. & 2247,82 & 2272,49 & 2400,89 & 2308,56 & 2341,6 & 2352,88 & 2468,25 & 2487,82 & 2504,23 \\
\hline Кол-во, шт. & 60 & 60 & 60 & 60 & 60 & 60 & 60 & 60 & 60 \\
\hline Общая Стоимость, руб. & 134869,2 & 136349,4 & 144053,4 & 138513,6 & 140496 & 141172,8 & 148095 & 149269,2 & 150253,8 \\
\hline Доходность, в процентах & & 0,01 & 0,05 & $-0,03$ & 0,01 & 0,01 & 0,04 & 0,01 & 0,01 \\
\hline
\end{tabular}

Таблица 8.

\begin{tabular}{|c|c|}
\multicolumn{2}{|c|}{ Корреляция активов } \\
\hline Активы & Коэффициент корреляции \\
\hline АБ & 0,58 \\
\hline АВ & 0,37 \\
\hline АГ & 0,16 \\
\hline АД & 0,03 \\
\hline БВ & 0,3 \\
\hline БГ & $-0,43$ \\
\hline БД & 0,34 \\
\hline ВГ & 0,34 \\
\hline ВД & 0,12 \\
\hline ГД & $-0,37$ \\
\hline
\end{tabular}

Таблица 9.

Доля и стандартное отклонение актива

\begin{tabular}{|c|c|c|}
\hline Актив & Доля в портфеле, в процентах & Стандартное отклонение, в процентах \\
\hline А & 26,85 & 5,64 \\
\hline Б & 30,78 & 3,24 \\
\hline В & 11 & 8,13 \\
\hline Г & 7,96 & 0,03 \\
\hline Д & 23,65 & 4,98 \\
\hline
\end{tabular}


получаем стандартное отклонение портфеля, которое равно $4,95 \%$.

Данный показатель говорит о том, что доходность портфеля должна будет колебаться в данном диапазоне, то есть мы можем ожидать, что доходность портфеля, за определенный период времени будет равна 10,53\% \pm 4,95\%, что позволяет ожидать получение дохода, даже в самом неблагоприятном случае для инвестора.

Найдя стандартное отклонение портфеля, рассчитаем коэффициент Шарпа, однако также понадобится ожидаемая доходность портфеля и ставка безрискового актива. За данный актив возьмем ставку по вкладу в сбербанк, которая составляет 5,75\%. Подставляем данные в формулу (2). Коэффициент Шарпа для портфеля получается 0,55.

Коэффициент Шарпа близок к единице - это означает, что ожидаемая доходность почти полностью компенсирует риск, который несет в себе портфель, однако, так как он все-таки не достигает единицы, нельзя утверждать, что доходности данного портфеля будет достаточно, чтобы покрыть риски. Из-за чего не можем быть на сто процентов уверены, что портфель эффективен, в добавок оценивать риски только по одному показателю, является не лучшей идеей, так как это может привести к тому, что инвестор упустит важные детали, которые в конечном итоге приведут к убытку.

После коэффициента Шарпа чаще всего рассчитывается коэффициент бета, который даст возможность понять, как взаимосвязан инвестиционный портфель и рынок. Или, иными словами, однонаправленна или разнонаправленна доходность рынка и портфеля.

Показатели для расчета бета-коэффициента

Таблица 10.

\begin{tabular}{|l|c|c|}
\hline & $\begin{array}{c}\text { Ковариация рынка и } \\
\text { портфеля, в процентах }\end{array}$ & $\begin{array}{c}\text { Дисперсия доходности } \\
\text { рынка, в процентах }\end{array}$ \\
\hline Значение & 10,27 & 8,52 \\
\hline
\end{tabular}

Применяя формулу (5), находим коэффициент бета, который равняется 1,2\%, что является невероятно большим значением, которое говорит о том, что изменение доходности рынка на 1\% приведет к изменению доходности портфеля на 1,2\% в одном направлении. Что делает портфель рискованным, так как доходность портфеля будет изменяться больше, чем доходность рынка. В связи с этим колебания рынка могут негативно сказаться на получении положительного эффекта от вложенных в портфель денежных средств.

Поняв, что наш портфель имеет высокий риск по отношению к рынку, мы должны определить, какую премию получим за данный риск и будет ли она достаточна, чтобы удовлетворить наши ожидания. Для этого воспользуемся коэффициентом Трейнора.

Для расчета нам понадобится доходность портфеля, доходность рынка и коэффициент бета.

Таблица 11.

Данные для расчета коэффициента Трейнора

\begin{tabular}{|l|c|c|c|}
\hline & $\begin{array}{r}\text { Доходность порт- } \\
\text { феля, в процентах }\end{array}$ & $\begin{array}{c}\text { Доходность рынка, } \\
\text { в процентах }\end{array}$ & $\begin{array}{c}\text { Бета коэффициент, } \\
\text { в процентах }\end{array}$ \\
\hline Данные & 10,53 & 11,17 & 1,2 \\
\hline
\end{tabular}

Найдем коэффициента Трейнора, подставим в формулу (рисунок 6), получаем -0,52.

Коэффициент Трейнора похож на коэффициент Шарпа, так как они оба сравнивают соотношение доходности к риску, в хорошо диверсифицированном портфеле коэффициенты друг с другом близки. Так как риск портфеля уменьшается до рыночного риска, то есть рыночное отклонение стремится к коэффициенту бета.

Сравнивая коэффициенты Шарпа и Трейнора, в собранном портфеле, можно увидеть, что они сильно друг от друга отличаются, что говорит о том, что портфель плохо диверсифицирован, что увеличивает риски.

Также стоит отметить, что коэффициент меньше нуля, который говорит, что доходность портфеля недостаточна для покрытия рисков, который несет в себе портфель.

Рассмотрев коэффициенты Шарпа, бета, Трейнора можно прийти к выводу, что портфель является высокорискованным, так как рыночное отклонение может привести к потери вложенных средств. Однако для выяснения является ли данный портфель эффективным, необходимо также рассмотреть коэффициента Альфа Дженсена, с помощью которого определим насколько эффективно собран портфель относительно рынка, то есть сможем понять получим ли мы от управления портфеля больше, чем в среднем по рынку.

Для его расчета необходимы 4 показателя: средняя доходность портфеля, средняя доходность рынка, доходность безрискового актива и коэффициент бета портфеля.

Таблица 12.

Показатели для расчета коэффициента Альфа Дженсена

\begin{tabular}{|l|c|c|c|c|}
\hline & $\begin{array}{c}\text { доходность } \\
\text { портфеля, в } \\
\text { процентах }\end{array}$ & $\begin{array}{c}\text { доходность } \\
\text { рынка, в } \\
\text { процентах }\end{array}$ & $\begin{array}{c}\text { доходность } \\
\text { безрисково- } \\
\text { го актива, в } \\
\text { процентах }\end{array}$ & $\begin{array}{c}\text { коэффи- } \\
\text { циент бета } \\
\text { портфеля, в } \\
\text { процентах }\end{array}$ \\
\hline Показатели & 10,53 & 11,17 & 5,83 & 1,2 \\
\hline
\end{tabular}


Воспользуемся формулой (рисунок 7), подставив данные (таблица 12) находим, что коэффициент Альфа Дженса равен $-1,69 \%$.

При отрицательном коэффициенте Альфа становится понятно: средняя доходность фонда ниже эталона. Отрицательные значения коэффициента Альфа свидетельству- ют о проигрыше рынку по части качества управления.

Из выше сказанного следует, что собранный портфель недостаточно доходен относительно рынка.

В заключении, анализ является необходимым, чтобы оградить себя от ненужных рисков, а также для обеспечения максимально возможной доходности.

\section{ЛИТЕРАТУРА}

1. Ващенко М. Охота на одиночек и молчунов // Эксперт. - 2010. - №38 (532). - с. 130 -134.

2. Гасанов И., Ерешко А. Оптимальное управление портфелем дисконтных облигаций / Рынок ценных бумаг. №14, - 2017. - С. 19-27;

3. Краев А.О. Рынок долговых ценных бумаг: Учебное пособие для вузов/А.О. Краев, И.Н. Коньков, П.Ю. Малеев. -М.: Экзамен, 2019. - 512 .

4. Рубцов Б. Б. Мировые рынки ценных бумаг. -М.: Экзамен, 2019. - 448с.

5. Binder J. Stock Market Volatility and Economic Factors, College of Business, University of Illinois-Chicago, 2010.

6. Hall S., Urga G. Testing for Ongoing Efficiency in the Russian Stock Market. Cass Business School, 2009.

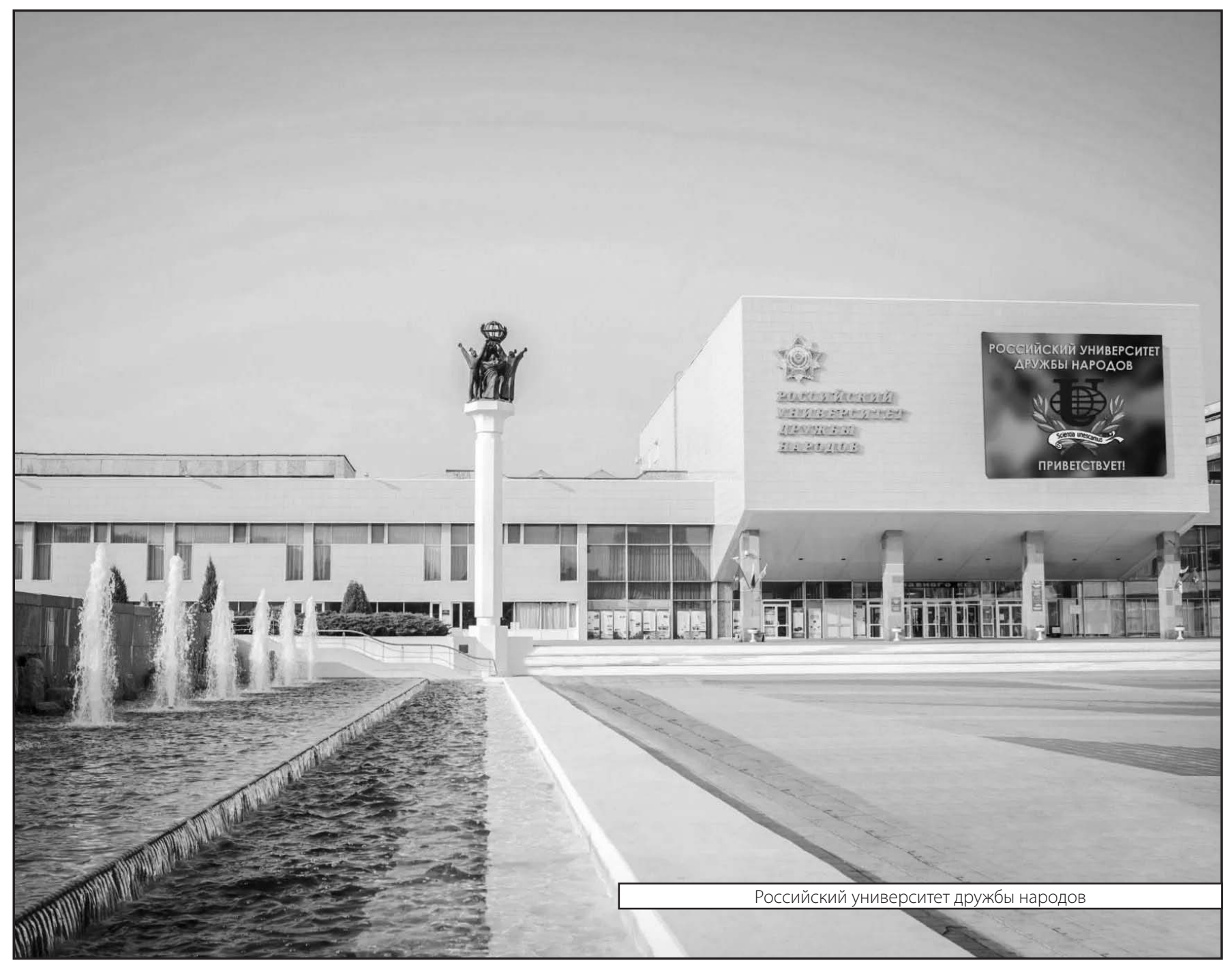

